\title{
A Meta-Analysis And Systematic Review Of Accuracy Of Endoscopic Ultrasound For N Staging Of Gastric Cancers
}

This article was published in the following Dove Press journal: Cancer Management and Research

Jiafei Chen

Chaoyang Zhou

Min $\mathrm{He}$

Zhiming Zhen

Jie Wang

Xiaofei Hu

Department of Radiology, Southwest Hospital, Third Military Medical

University (Army Medical University),

Chongqing, People's Republic of China

Correspondence: Xiaofei Hu

Department of Radiology, Southwest

Hospital, Third Military Medical

University (Army Medical University),

Chongqing 400038, People's Republic of

China

Tel +86-23-6876-5419

Fax +86-23-6546-3026

Email harryzonetmmu@163.com
Background: Endoscopic ultrasonography (EUS) is widely used as a staging modality for gastric cancer. However, the results of studies on the use of EUS for N staging in gastric cancer vary. This study aimed at studying the overall diagnostic accuracy of EUS for $\mathrm{N}$ staging of gastric cancer.

Methods: Published studies were identified through searching the MEDLINE, Web of Science, EMBASE, SpringerLink and ScienceDirect databases. A bivariate random effect model was used to estimate the sensitivity, specificity, positive likelihood ratio (PLR), negative likelihood ratio (NLR), and diagnostic odds ratio (DOR). A hierarchical summary receiver operating characteristic curves (HSROC) based on the pooled data was also computed.

Results: Fifty studies (5223 patients) were included in this analysis. The pooled sensitivity, specificity, PLR, NLR and DOR of EUS for N staging were 0.82 (95\% CI 0.78 to 0.85 ), 0.68 ( 0.63 to 0.73 ), 2.6 (2.2 to 3.0$), 0.27$ ( 0.22 to 0.32 ), and 10 (8 to 12), respectively. The area under the HSROC was 0.83 .

Conclusion: The EUS may provide a clinically useful tool to guide physicians in the $\mathrm{N}$ staging of gastric cancer. However, physicians must note that the EUS has a relatively low specificity.

Keywords: gastric cancer, N staging, endoscopic ultrasound, meta-analysis

\section{Introduction}

Gastric cancer remains the second leading cause of cancer deaths worldwide. ${ }^{1}$ The treatment of gastric cancer patients depends on the exact assessment of gastric staging. The prognosis of patients with gastric cancer is also determined by the progress of the tumor, including lymph node metastasis and tumor invasion outside the stomach wall. ${ }^{2,3}$ More accurate staging methods are required to achieve the most effective treatment, thus leading to longer survival and better quality of life.

Preoperative understanding of clinical staging in gastric cancer is very useful in providing the best treatment for patients: for example, neoadjuvant (preoperative) chemotherapy can be used to treat AGC (i.e., tumors with lymph node metastases $(\mathrm{N}+)) .^{4,5}$ In addition, early gastric cancer without lymph node metastasis (T1 tumors) (N0) can be resected through endoscopic without surgery. ${ }^{6,7}$ However, patients with gastric cancer with lymph node metastasis may have a lower survival rate and a higher risk of recurrence if they are treated through surgery alone. Thus, lymph node status is important in guiding treatment and predictive outcomes. 
Several tools to diagnose lymph node metastasis of gastric cancer are available, such as multi-detector computed tomography (MDCT), positron emission tomography/computed tomography (PET/CT), magnetic resonance imaging (MRI), and endoscopic ultrasonography (EUS) ${ }^{8}$ MDCT is most widely used to assess lymph node staging of gastric cancer patients, mainly on the basis of lymph node size, ${ }^{9,10}$ but the limited sensitivity of MDCT results in false-negative findings. ${ }^{9,11}$ The overall accuracy and sensitivity of MDCT for $\mathrm{N}$ staging were about 63.864\%, 43.3-55\%. ${ }^{12,13}$ Diffusion-weighted imaging (DWI) and 18 F-Fluorodeoxyglucose PET/CT (18 F-FDG PET/ $\mathrm{CT})$ are relatively new imaging techniques used for preoperative staging of numerous cancers and both achieved a higher sensitivity and specificity than MDCT. ${ }^{14}$ Despite the continuous improvement of imaging technology, the accuracy of $\mathrm{N}$ staging of gastric cancer is still very low. ${ }^{15}$

EUS in the staging of gastric cancer was first introduced in clinical practice in the $1980 \mathrm{~s}$, and it has been slow to accept as an important part of gastric cancer staging assessment. EUS can assess the depth of tumor invasion and whether the lymph nodes are involved. But its shortcomings include a high degree of reliance on the operator, the need for very professional technical skills, the inability to detect plane or fix lesions, and the inability to assess long-distance transfers. ${ }^{16,17}$

EUS was useful in assessing gastric cancer T staging. Previous studies have found that the EUS diagnostic accuracy for $\mathrm{T}$ staging ranges from $43 \%$ to $88 \% .{ }^{18-22}$ However, the conclusions in studies on the accuracy of EUS in detecting lymph node metastasis of gastric cancer vary. Our study was conducted to review and perform a metaanalysis regarding the use of EUS in assessing the diagnostic accuracy of gastric cancer lymph node metastasis ( $\mathrm{N}$ stage).

\section{Materials And Methods}

\section{Study Selection Criteria}

Only gastric cancer cases confirmed by surgery preceded by EUS were included. For lymph node status ( $\mathrm{N}$ stage), if there was no lymph node metastasis (N0) according to pathology, the patient was considered negative, whereas if one or more lymph nodes were metastatic $(\mathrm{N}+)$, the patient was considered positive. The EUS criteria used for the nodal invasion were lymph node morphology and size. Only studies containing a $2 \times 2$ table that could be extracted or calculated from for true-negative (TN), false- negative (FN), true-positive (TP), and false-positive (FP) results were included. All selected studies were previously published; thus, no ethical approval or patient consent was required.

Studies were excluded for the following reasons: i) the prognostic information for lymph node status was not reported in the studies; ii) the TN, FN, TP, and FP results could not be calculated considering the originally published data or could not get by email with corresponding author; and iii) especially, studies in which patients received neoadjuvant therapy were excluded because they might have biased the results through "downstaging" regression of lymph nodes.

\section{Data Sources And Searches}

A comprehensive electronic search of the MEDLINE, Web of Science, EMBASE, SpringerLink, and ScienceDirect databases was performed by two investigators to identify relevant articles published before April 2019 by two investigators. The search keywords used included: EUS, endoscopic ultrasound, ultrasound, gastric cancer, stomach neoplasm, tumor staging, staging, lymph nodes, metastasis, sensitivity, specificity, positive predictive value, and negative predictive value.

The species was defined as "human." We did not limit our search to publications from certain countries, but only articles published in English were identified. To retrieve additional publications, we manually searched reference lists from the included articles and relevant systematic and narrative reviews on the topic. We imported all citations identified in the databases above into a bibliographic database (EndNote, version X7, Thomson Reuters).

\section{Data Extraction And Quality Assessment}

To obtain $2 \times 2$ contingency tables from the included studies, TN, FN, TP, and FP results were extracted or calculated. The two authors independently searched and extracted the data. Any differences were resolved through mutual agreement.

Quality assessment of the included studies was performed by two independent reviewers using the recently developed version 2 of the Quality Assessment of Diagnostic Accuracy Studies (QUADAS-2) tool for diagnostic accuracy studies. ${ }^{23}$ Data extraction and quality assessment were performed by the same two researchers independently, and a consensus was reached when disagreements arose. 


\section{Data Synthesis And Analysis}

Stata, version 12.0 (Stata Corp., College Station, TX, USA) with the "midas" and "metandi" commands was used. ${ }^{24}$ We performed meta-analysis with the bivariate random effects model to calculate the sensitivity and specificity of the combined diagnostic odds ratio (DOR) and EUS performance from diagnostic test data. In addition, hierarchical summary receiver operating characteristic (HSROC) curves based on the pooled data were computed for EUS performance and the area-under-the-curve (AUC) index for each technique. Then, we determined whether the differences in all indicators (sensitivity, specificity, and DOR) between different modalities were statistically significant by using the $Z$ test. All $\mathrm{p}$ values presented are twosided, and the results were considered significant only if the $p$ value was less than or equal to 0.05 .

A "shoulder-arm" shape in the ROC plane can suggest a threshold effect. The $\mathrm{Q}$ statistic of the chi-square test and the inconsistency index $\left(\mathrm{I}^{2}\right)$ were used to estimate the heterogeneity between included studies, and $\mathrm{p}<0.1$ or $\mathrm{I}^{2}$ $>50 \%$ indicated heterogeneity. ${ }^{25}$

We expected to find between-study variation in the analysis results, as is common in diagnostic accuracy studies. Subgroup analysis was used to assess the effects of various factors on the diagnostic accuracy of EUS and to investigate the potential sources of heterogeneity; we additionally performed meta-regression with the bivariate model including covariates (publication year, country, study sample size, type of EUS array, and stomach site).

Publication bias was assessed through an asymmetry test and Deeks' funnel plot in Stata. ${ }^{26}$ An inverted symmetrical funnel plot with $p>0.05$ was considered to indicate the absence of publication bias.

\section{Results}

We identified 2328 reference articles by using the search criteria. Among these, the two authors independently selected and reviewed 376 relevant full-text articles. Finally, 50 studies $(n=5223)$, which were published as full-text articles in peer-reviewed journals, were included in the meta-analysis. ${ }^{21,27-75}$ The details of the included studies are shown in Figure 1, the PRISMA checklist and Table 1.

Figure 2 shows that QUADAS2 criteria were used to assess the quality of the eligible studies; the values ranged from $20 \%$ to $100 \%$ high-quality studies in the four domains of the bias part and three domains of the applicability part. For most QUADAS2 domains (3/4), all studies were classified as high quality.

\section{Lymph Node Status (N-Stage)}

The combined values of sensitivity, specificity, likelihood ratio, and DOR, as well as the values for the single studies, are displayed in Figure 3. Figure 4 shows the HSROC curve including the summary point and its $95 \%$ confidence and prediction intervals.

The summary sensitivity, specificity, positive likelihood ratio (PLR), negative likelihood ratio (NLR), and DOR were 0.82 (95\% CI 0.78 to 0.85$), 0.68$ (95\% CI 0.63 to 0.73$), 2.6$ (95\% CI 2.2 to 3.0$), 0.27$ (95\% CI 0.22 to 0.32$)$, and 10 (95\% CI 8 to 12$)$, respectively, and the HSROC area AUROC was $0.83(0.79-0.86)$. The summary sensitivity (but not specificity) was relatively high, but the forest plot showed that the between-study heterogeneity was substantial (Figure 3). The Fagan plot (Figure 5) indicated that the previous probability of being classified as $\mathrm{N}+$ increased from $50 \%$ (average prevalence of $\mathrm{N}+$ cases) to $70 \%$ when positive, and decreased to $20 \%$ when negative, when EUS was used, thus indicating that EUS may be clinically informative.

The between-study heterogeneity was significant both for sensitivity $\left(\mathrm{I}^{2}: 79.35 \%\right.$, $\mathrm{Q}$ test $\left.\mathrm{P}=0.001\right)$ and for specificity ( $\mathrm{I}^{2}: 91.4 \%$, Q test $\left.\mathrm{P}=0.001\right)$. The proportion of heterogeneity was substantial (47\%), probably because of the threshold effect. Subgroup and sensitivity analyses (Table 2) showed that the publication year was related to the heterogeneity. No evidence of notable publication bias was found according to Deeks' funnel plot asymmetry test.

\section{Discussion}

This system evaluated data from many lines of research including large series of patients $(n=5223)$ to assess the diagnostic performance of EUS in gastric cancer $\mathrm{N}$ staging. Using the statistical methods of diagnostic metaanalysis, we quantified the existing evidence and found that EUS might be clinically informative for gastric cancer $\mathrm{N}$ staging overall. This study may provide clinically useful information for physicians for making clinical decisions.

This meta-analysis indicated that the sensitivity of EUS for gastric cancer $\mathrm{N}$ staging was relatively high (82\%). However, the specificity of EUS in the diagnosis of $\mathrm{N}$ 


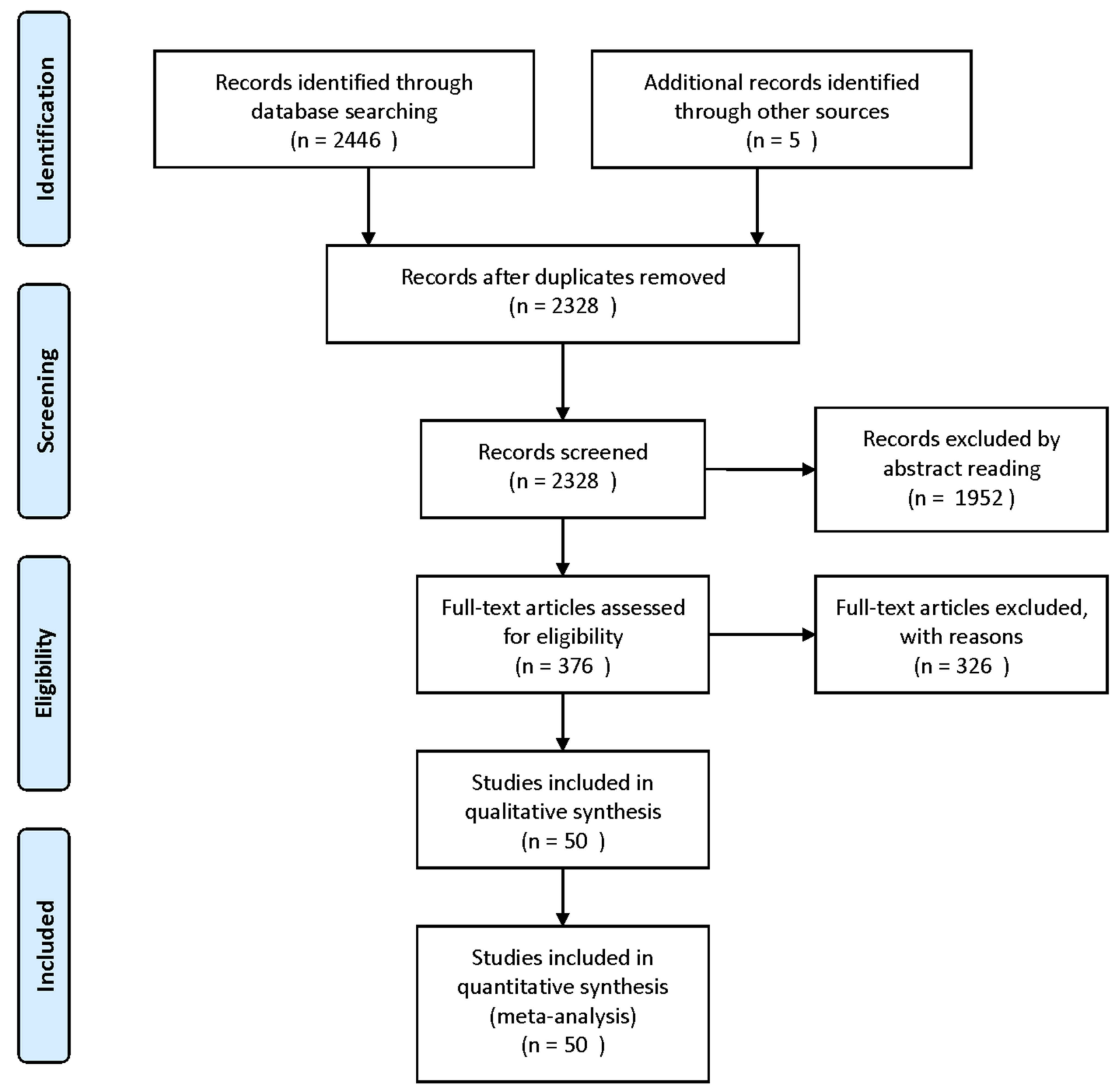

Figure I Flowchart illustrating the selection of studies.

staging in gastric cancer was not high (68\%). Moreover, the EUS also had a relatively high PLR (2.6) and a relatively low NLR (0.27), thus indicating that EUS performs well in identifying the true lymph node status (positive) and in excluding false lymph node status (negative). In addition, EUS had a relatively high DOR (10) in the diagnosis of $\mathrm{N}$ staging of gastric cancer, thus indicating that EUS performs better at diagnosing than excluding $\mathrm{N}$ staging in gastric cancer. The heterogeneity between different studies was determined with HSROC curves. The HSROC curves for EUS showed that the value for the area under the curve was very close to $1(0.83)$, thus indicating that EUS is a good diagnostic test for $\mathrm{N}$ staging in gastric cancers.

Our findings support the potential value of EUS in $\mathrm{N}$ staging in gastric cancer. Although this method is not the first choice, it is considered clinically useful to guide doctors in disease staging and then choosing the 
Table I Main Features Of The 50 Eligible Studies $(N=5223)$ Included Studies

\begin{tabular}{|c|c|c|c|c|c|c|}
\hline ID & Sample Size & Country & Conformatory Test & Equipment & Frequency $(\mathbf{M H z})$ & Stomach Site \\
\hline Tio et al, $1986^{27}$ & 11 & Netherlands & Surgery & Radial & Unreported & Any \\
\hline Murata et al, $1988^{28}$ & 146 & Japan & Surgery & Radial & $7.5-10$ & Any \\
\hline Tio et al, $1989^{29}$ & 80 & Netherlands & Surgery & Radial & $7.5-12$ & Any \\
\hline Botet et al, $|99|^{30}$ & 50 & United states & Surgery & Radial & $7.5-12$ & Any \\
\hline Cerizzi et al, $|99|^{31}$ & 21 & Italy & Surgery & Radial & $7.5-12$ & Any \\
\hline Caletti et al, $1993^{32}$ & 35 & Italy & Surgery & Radial & $7.5-12$ & Any \\
\hline Dittler et al, $1993^{33}$ & 254 & Germany & Surgery & Radial & $7.5-12$ & Any \\
\hline Grimm et al, $1993^{34}$ & 147 & Germany & Surgery & Radial & 7.5 & Any \\
\hline Ziegler et al, $1993^{35}$ & 108 & Germany & Surgery & Radial & $7.5-20$ & Any \\
\hline Francois et al, $1996^{36}$ & 29 & France & Surgery & Radial & $7.5-12$ & Cardia \\
\hline Massari et al, $1996^{37}$ & 65 & Italy & Surgery & Radial & $7.5-12$ & Any \\
\hline Perng et al, $1996^{38}$ & 76 & Taiwan & Surgery & Radial & $7.5-12$ & Any \\
\hline Hamada et al, $1997^{39}$ & 149 & Japan & Surgery & Radial & $7.5-20$ & Any \\
\hline Akahoshi et al, $1998^{40}$ & 73 & Japan & Surgery & Radial & 15 & Any \\
\hline Hunerbein et al, $1998^{41}$ & 22 & Germany & Surgery & Radial & 12.5 & Any \\
\hline Wang et al, $1998^{42}$ & 119 & Taiwan & Surgery & Radial & $7.5-12$ & Any \\
\hline De Manzoni et al, $1999^{43}$ & 29 & Italy & Surgery & Radial & 7.5 & Cardia \\
\hline Nakamura et al, $1999^{44}$ & 31 & Japan & Surgery & NR & NR & Any \\
\hline Mancino et al, $2000^{45}$ & 79 & Italy & Surgery & Radial & $7.5-12$ & Any \\
\hline Tseng et al, $2000^{46}$ & 74 & Taiwan & Surgery & Radial & $7.5-12$ & Any \\
\hline Willis et al, $2000^{47}$ & 116 & Germany & Surgery & Radial & $7.5-12$ & Any \\
\hline Chen et al, $2002^{48}$ & 57 & Taiwan & Surgery & Radial & $7.5-20$ & Any \\
\hline Xi et al, $2003^{49}$ & 32 & China & Surgery & Radial & $7.5-20$ & Any \\
\hline Bhandari et al, $2004^{50}$ & 48 & Korea & EMR or Surgery & Radial & 20 & Any \\
\hline Habermann et al, $2004^{51}$ & 51 & Germany & Surgery & Radial & $7.5-12$ & Any \\
\hline Javaid et al, $2004^{52}$ & 112 & India & Surgery & Radial & 7.5 & Any \\
\hline Polkowski et al, $2004^{53}$ & 88 & Poland & Surgery & Radial & $7.5-12$ & Any \\
\hline Shimoyama et al, $2004^{54}$ & 45 & Japan & Surgery & Linear & 7.5 & Cardia \\
\hline Lee et al, $2005^{55}$ & 241 & China & Surgery & Linear & $7.5,12$ & Any \\
\hline Pedrazzani et al, $2005^{56}$ & 51 & Italy & Surgery & Linear & 7.5 & Cardia \\
\hline Ang et al, $2006^{57}$ & 57 & Singapore & Surgery & Radial & $7.5-12$ & Any \\
\hline Arocena et al, $2006^{58}$ & 17 & Spain & Surgery & Linear & 12.5 & Any \\
\hline Ganpathi et al, $2006^{59}$ & 102 & Singapore & Surgery & Radial & $7.5-12$ & Any \\
\hline Potrc et al, $2006^{60}$ & 82 & Slovenia & Surgery & Radial & $7.5-12$ & Any \\
\hline Tsendsuren et al, $2006^{61}$ & 41 & China & Surgery & Linear & $5-7.5$ & Any \\
\hline Barbour et al, $2007^{62}$ & 206 & USA & Surgery & Radial & $7.5-12$ & Cardia \\
\hline Bentrem et al, $2007^{63}$ & 218 & United States & Surgery & NR & $7.5-12$ & Any \\
\hline Tan et al, $2007^{64}$ & 63 & China & Surgery & Radial & $7.5-20$ & Any \\
\hline Blackshaw et al, $2008^{65}$ & 44 & UK & Surgery & Radial & $7.5-12$ & Cardia \\
\hline Lok et al, $2008^{66}$ & 75 & Hong Kong & Surgery & Radial & $12-20$ & Any \\
\hline Park et al, $2008^{67}$ & 40 & Korea & Surgery & Radial & $7.5--12$ & Any \\
\hline Ahn et al, $2009^{68}$ & 71 & Korea & Surgery & Radial & $5-12$ & Any \\
\hline Hwang et al, $2010^{21}$ & 277 & Korea & Surgery & Radial & $5-20$ & Any \\
\hline Repiso et al, $2010^{69}$ & 36 & Spain & Surgery & Radial & $7.5-20$ & Any \\
\hline Bohle et al, 201 I & 62 & Germany & Surgery & Radial & 20 & Any \\
\hline Zheng 201 $\mathrm{I}^{71}$ & 165 & China & Surgery & Radial & $7.5-12$ & Any \\
\hline Kutup et al, $2012^{72}$ & 123 & Germany & Surgery & Radial & $7.5-12$ & Any \\
\hline Spolverato et al, $2015^{73}$ & 149 & USA & Surgery & Radial & $7.5-12$ & Any \\
\hline Giganti et al, $2016^{74}$ & 52 & Italy & Surgery & Radial & $5-10$ & Any \\
\hline Serrano et al, $2016^{75}$ & 69 & USA & Surgery & Radial & $7.5,10$ & Any \\
\hline
\end{tabular}




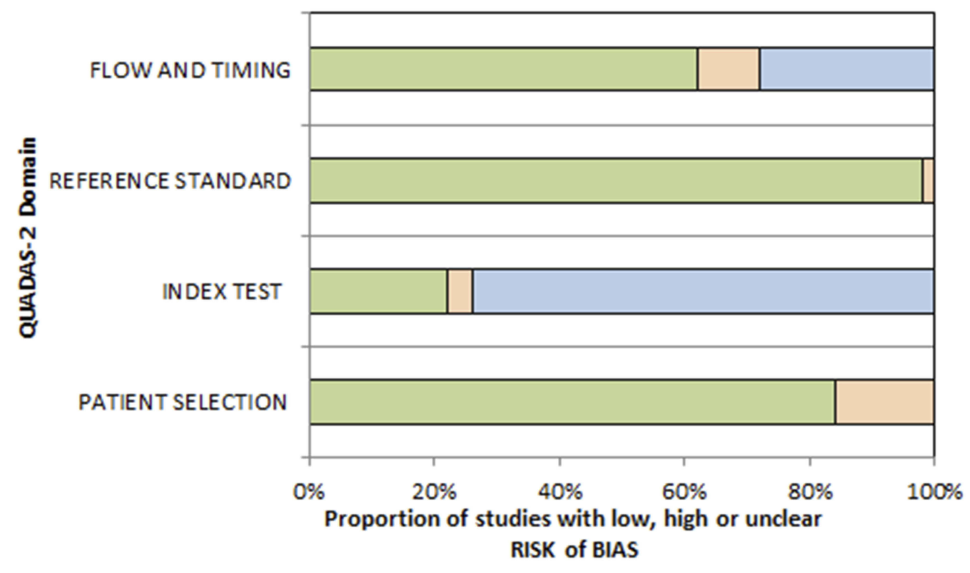

口Low $\square$ High $\square$ Unclear

Figure 2 Graphical display for QUADAS-2 results regarding the proportion of studies with low, high, or unclear risk of bias.
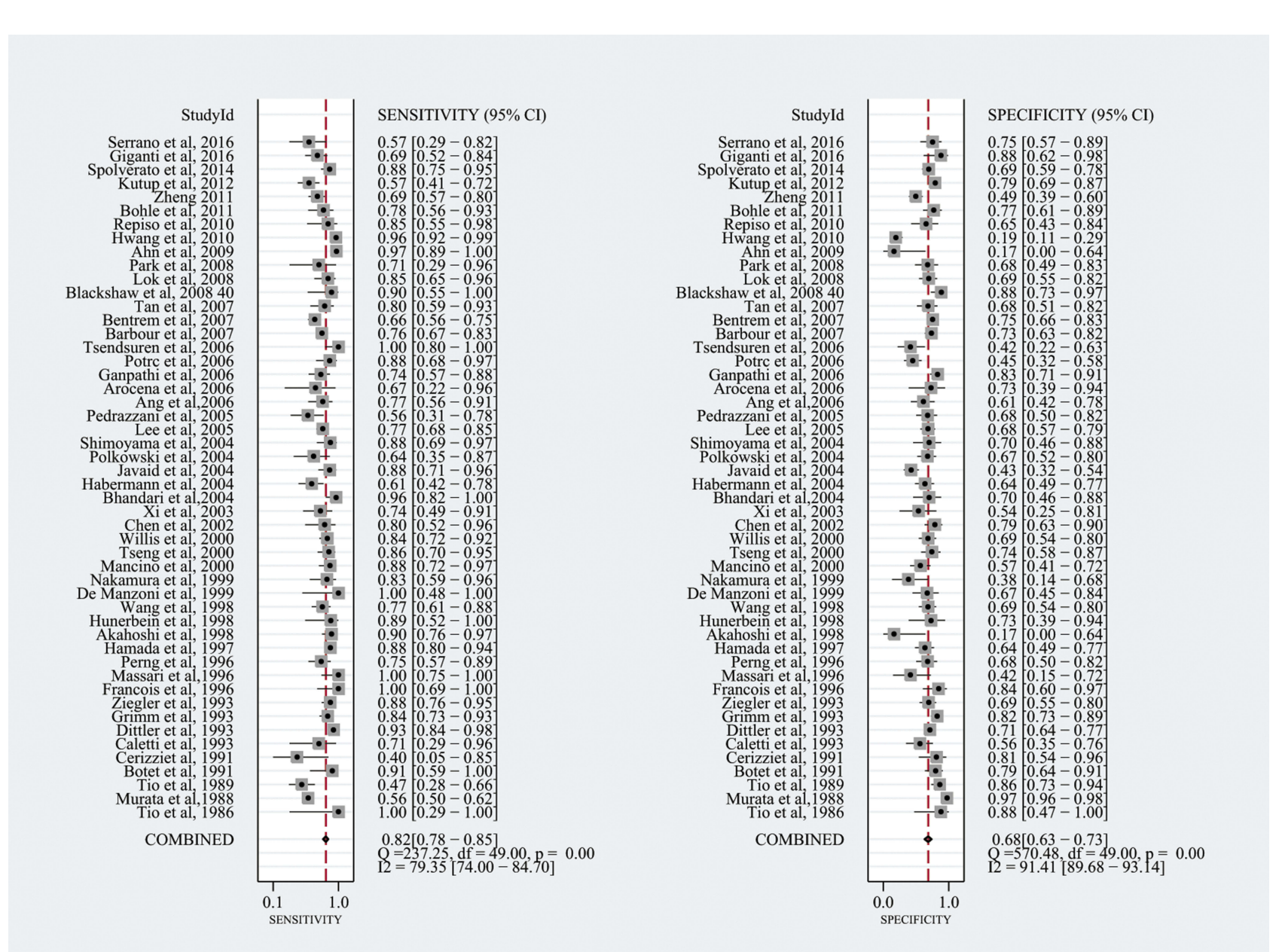

Figure 3 EUS diagnostic performance to distinguish lymph node-positive from lymph node-negative tumors: forest plot of the studies included in the meta-analysis.

most appropriate individual treatment strategy according to personalized medicine principles. However, physicians must note that EUS has relatively low specificity in diagnosing lymph node status (positive versus negative).

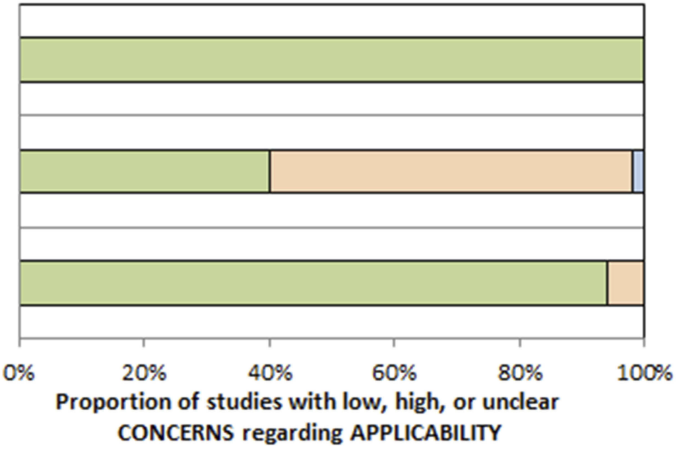

CONCERNS regarding APPLICABILITY
EUS has unparalleled advantages over other alternative options: it does not require general anesthesia or hospitalization, and the inspection process is safe and minimally invasive, with a low incidence of complications. ${ }^{76-79}$ 


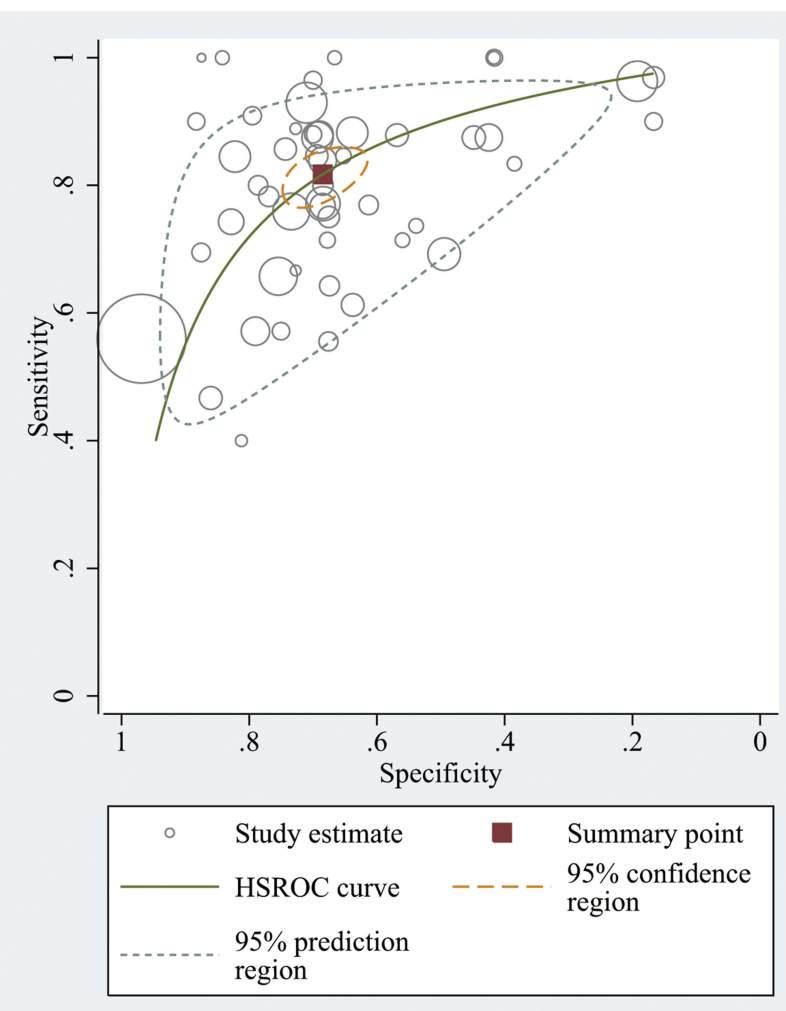

Figure 4 Hierarchic summary receiver operating characteristic (ROC) (solid line) plot with summary point with $95 \% \mathrm{Cl}$ area (circled area).

We observed considerable heterogeneity among the study results, and we performed subgroup analysis and meta-regression. The EUS criteria for nodal metastasis and the technology of EUS have improved over the past two decades. This improvement has affected the staging of gastric cancer and has contributed to most of the heterogeneity. However, this change did not greatly improve $\mathrm{N}$ staging, and although the pooled specificity of EUS is high, the sensitivity is not as high. Publication bias did not significantly affect the summary estimates, as shown in funnel plots in this meta-analysis.

MDCT is most widely used to assess lymph node staging in gastric cancer patients, mainly on the basis of lymph node size, thus potentially leading to insufficient staging when the most recent edition (7th, 2010) of the AJCC TNM classification is used. ${ }^{80}$ When $\mathrm{N}$ stages are determined through MRI examination, there are effects of factors such as long examination times, gastrointestinal peristalsis, and multiple breath-holding times. PET examination is insensitive to metastatic lymph nodes $<5 \mathrm{~mm}$, owing to gastric physiological uptake and creep, limitations of the inherent resolution, and primary tumor uptake coverage.

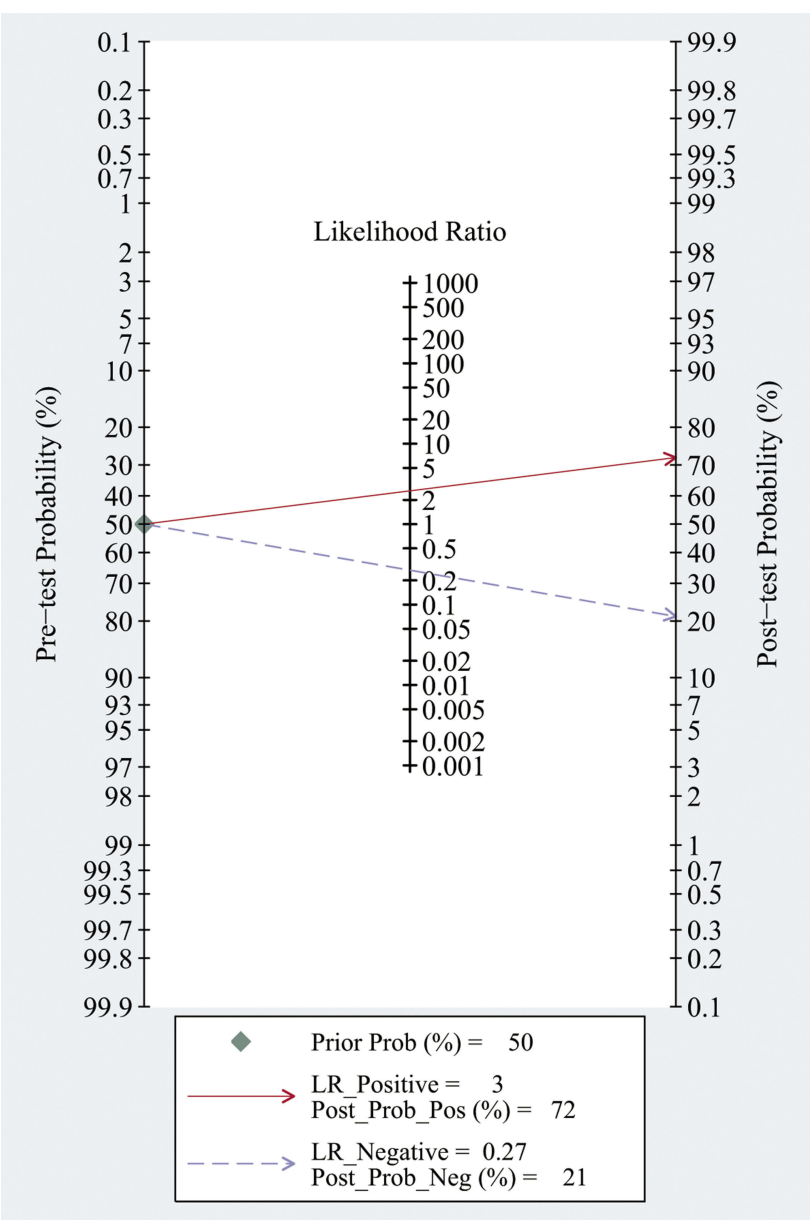

Figure 5 EUS diagnostic performance to distinguish lymph node-positive from lymph node-negative tumors: Fagan plot (Bayesian nomogram).

The advantage of EUS is its ability to differentiate the layers of the gastric mucosa. Notably, the accuracy of EUS in staging gastric cancers varies, and EUS has been reported to understage the depth of invasion and overstage nodal invasion because of inflammation in the lymph nodes and extension greater than $20 \mathrm{~mm},{ }^{81}$ which physicians should mind.

There are several strengths of this review, primarily the number of patients enrolled ( $n=5223)$. A large number of patients enrolled ensures good representation of the results and improves statistical performance. Moreover, we provided relatively comprehensive meta-analysis indexes to add further information regarding clinical use, from summary diagnostic performance to Bayesian analysis including Fagan plots and likelihood ratio matrices. There are several limitations of this study, primarily the markedly high heterogeneity, which may have limited the reliability and reproducibility. Furthermore, the data available in the literature did the challenges for the identification of possible 
Table 2 Subgroup And Sensitivity Analysis For N0 Versus N+ Gastric Tumors

\begin{tabular}{|l|l|l|l|l|l|}
\hline Variable & Category & Studies & Sensitivity (95\% Cl) & Specificity (95\% Cl) & P Value \\
\hline Sample size & $>100$ & 14 & $0.82[0.76-0.88]$ & $0.70[0.61-0.78]$ & $0.68[0.62-0.75]$ \\
& $<100$ & 36 & $0.82[0.77-0.87]$ & 0.96 \\
\hline Year of publication & 2000 or later & 32 & $0.81[0.76-0.86]$ & $0.66[0.60-0.72]$ \\
& Before 2000 & 18 & $0.85[0.79-0.91]$ & $0.74[0.67-0.82]$ \\
\hline Country & Western & 28 & $0.79[0.73-0.85]$ & $0.73[0.67-0.79]$ & 0.02 \\
& Eastern & 22 & $0.85[0.81-0.90]$ & $0.64[0.56-0.71]$ & 0.12 \\
\hline EUS array & Radial & 44 & $0.82[0.78-0.86]$ & $0.70[0.64-0.75]$ & $0.62[0.46-0.78]$ \\
\hline Tumor site & Linear & 6 & $0.84[0.74-0.94]$ & $0.76[0.63-0.88]$ & 0.67 \\
& Cardia region & 6 & $0.83[0.71-0.94]$ & $0.68[0.62-0.73]$ \\
\hline
\end{tabular}

heterogeneity. Further network meta-analyses may address some of the problems described above.

\section{Disclosure}

The authors reports no conflict of interest in this work.

\section{References}

1. Torre LA, Siegel RL, Ward EM, Jemal A. Global cancer incidence and mortality rates and trends - an update. Cancer Epidemiol Biomarkers Prev. 2015;25:1

2. Jin Z, Jiang W, Wang L. Biomarkers for gastric cancer: progression in early diagnosis and prognosis. Lancet. 2015;268(6938):859-861.

3. Marrelli D, Polom K, de Manzoni G, Morgagni P, Baiocchi GL, Roviello F. Multimodal treatment of gastric cancer in the west: where are we going? World J Gastroenterol. 2015;21(26):7954. doi:10.3748/ wjg.v21.i26.7954

4. Jiang Y, Ajani JA. Multidisciplinary management of gastric cancer. Curr Opin Gastroenterol. 2010;26(6):640-646. doi:10.1097/ MOG.0b013e32833efd9b

5. Paoletti X, Oba K, Burzykowski T, et al. Benefit of adjuvant chemotherapy for resectable gastric cancer: a meta-analysis. JAMA. 2010;303(17):1729-1737. doi:10.1001/jama.2010.534

6. Niwa Y, Miyahara R, Goto H. Endoscopic Submucosal Dissection of Early Gastric Cancer and Gastric Tumors[M]//Interventional and Therapeutic Gastrointestinal Endoscopy. Karger Publishers, 2010;27:156-168

7. Sanchezyague A, Gonzalezcanoniga A, Sanchezcantos AM, Soetikno R. "Unchaining" a stuck early gastric cancer by endoscopic submucosal dissection. Gastrointest Endosc. 2014;81(5):1253-1254. doi:10. 1016/j.gie.2014.07.010

8. Hwang SW, Dong HL. Is endoscopic ultrasonography still the modality of choice in preoperative staging of gastric cancer? World $J$ Gastroenterol WJG. 2014;20(38):13775. doi:10.3748/wjg.v20.i38.13 775

9. Fujikawa H, Yoshikawa T, Hasegawa S, et al. Diagnostic value of computed tomography for staging of clinical T1 gastric cancer. Ann Surg Oncol. 2014;21(9):3002-3007. doi:10.1245/s10434-0143667-9

10. Park HS, Kim YJ, Ko SY, et al. Benign regional lymph nodes in gastric cancer on multidetector row CT. Acta Radiol. 2012;53 (5):501-507. doi:10.1258/ar.2012.120054
11. Kim SH, Kim JJ, Lee JS, et al. Preoperative N staging of gastric cancer by stomach protocol computed tomography. J Gastric Cancer. 2013;13(3):149-156. doi:10.5230/jgc.2013.13.3.149

12. Joo I, Lee JM, Kim JH, Shin CI, Han JK, Choi BI. Prospective comparison of $3 \mathrm{~T}$ MRI with diffusion-weighted imaging and MDCT for the preoperative TNM staging of gastric cancer. $J$ Magn Reson Imaging. 2015;41(3):814-821. doi:10.1002/ jmri. 24586

13. Cimavilla Roman M, de la Serna Higuera C, Loza Vargas LA, et al. Endoscopic ultrasound versus multidetector computed tomography in preoperative gastric cancer staging. Rev esp de enfermedades digestivas. 2017;109(11):761-767. doi:10.17235/reed.2017.4638/2016

14. Luo M, Song H, Liu G, et al. Comparison of DWI and 18F-FDG $\mathrm{PET} / \mathrm{CT}$ for assessing preoperative N-staging in gastric cancer: evidence from a meta-analysis. Oncotarget. 2017;8(48):84473. doi:10. 18632/oncotarget. 21055

15. Seevaratnam R, Cardoso R, Mcgregor C, et al. How useful is preoperative imaging for tumor, node, metastasis (TNM) staging of gastric cancer? A meta-analysis. Gastric Cancer. 2012;15 Suppl 1 (1):3-18. doi:10.1007/s10120-011-0069-6

16. Cardoso R, Coburn N, Seevaratnam R, et al. A systematic review and meta-analysis of the utility of EUS for preoperative staging for gastric cancer. Gastric Cancer. 2012;15(1):19-26. doi:10.1007/s10120-0110115-4

17. Trindade AJ, Berzin TM. Clinical controversies in endoscopic ultrasound. Gastroenterol Rep. 2013;1(1):33-41. doi:10.1093/gastro/got0 10

18. Meyer L, Meyer F, Schmidt U, Gastinger I, Lippert H. Endoscopic ultrasonography (EUS) in preoperative staging of gastric cancer demand and reality. Pol J Surg. 2012;84(3):152-157. doi:10.2478/ v10035-012-0024-1

19. Han C, Lin R, Shi H, et al. The role of endoscopic ultrasound on the preoperative $\mathrm{T}$ staging of gastric cancer: a retrospective study. Medicine. 2016;95:36. doi:10.1097/MD.0000000000004864

20. Yu T, Wang X, Zhao Z, et al. Prediction of $\mathrm{T}$ stage in gastric carcinoma by enhanced CT and oral contrast-enhanced ultrasonography. World J Surg Oncol. 2015;13(1):1-8. doi:10.1186/1477-781913-1

21. Hwang SW, Lee DH, Lee SH, et al. Preoperative staging of gastric cancer by endoscopic ultrasonography and multidetector-row computed tomography. J Gastroenterol Hepatol. 2010;25(3):512-518. doi:10.1111/j.1440-1746.2009.06106.x

22. Cho JW. The role of endoscopic ultrasonography in T staging: early gastric cancer and esophageal cancer. Clin Endosc. 2013;46(3):239242. doi:10.5946/ce.2013.46.3.239 
23. Whiting PF, Rutjes AW, Westwood ME, et al. QUADAS-2: a revised tool for the quality assessment of diagnostic accuracy studies. Ann Intern Med. 2011;155(8):529-536. doi:10.7326/0003-4819-155-8-20 1110180-00009

24. Harbord RM, Whiting P. Metandi: meta-analysis of diagnostic accuracy using hierarchical logistic regression. Stata J. 2009;9(2):211229. doi:10.1177/1536867X0900900203

25. Higgins JPT, Thompson SG, Deeks JJ, Altman DG. Measuring inconsistency in meta-analyses. $\mathrm{Br}$ Med J. 2003;327(7414):557560. doi:10.1136/bmj.327.7414.557

26. Deeks JJ, Macaskill P, Irwig L. The performance of tests of publication bias and other sample size effects in systematic reviews of diagnostic test accuracy was assessed. J Clin Epidemiol. 2005;58 (9):882-893. doi:10.1016/j.jclinepi.2005.01.016

27. Tio TL, Den Hartog Jager FC, Tytgat GN. The role of endoscopic ultrasonography in assessing local resectability of oesophagogastric malignancies. Accuracy, pitfalls, and predictability. Scand $J$ Gastroenterol Supplement. 1986;123:78-86.

28. Murata Y, Suzuki S, Hashimoto H. Endoscopic ultrasonography of the upper gastrointestinal tract. Surg Endosc. 1988;2(3):180-183. doi:10.1007/bf02498796

29. Tio TL, Coene PP, Schouwink MH, Tytgat GN. Esophagogastric carcinoma: preoperative TNM classification with endosonography. Radiology. 1989;173(2):411-417. doi:10.1148/radiology.173.2.2678255

30. Botet JF, Lightdale CJ, Zauber AG, et al. Preoperative staging of gastric cancer: comparison of endoscopic US and dynamic CT. Radiology. 1991;181(2):426-432. doi:10.1148/radiology.181.2.1924784

31. Cerizzi A, Crosta C, Botti F, Carrara A, Alloni R, Taschieri A. Preoperative staging of gastric carcinoma using endosonography (EUS). Annali italiani di chirurgia. 1991;63(4):465-469; discussion 469-470.

32. Caletti G, Ferrari A, Brocchi E, Barbara L. Accuracy of endoscopic ultrasonography in the diagnosis and staging of gastric cancer and lymphoma. Surgery. 1993;113(1):14-27.

33. Dittler HJ, Siewert JR. Role of endoscopic ultrasonography in gastric carcinoma. Endoscopy. 1993;25(2):162-166. doi:10.1055/s-2007-10 10276

34. Grimm H, Binmoeller KF, Hamper K, Koch J, Henne-Bruns D, Soehendra N. Endosonography for preoperative locoregional staging of esophageal and gastric cancer. Endoscopy. 1993;25(3):224-230. doi:10.1055/s-2007-1010297

35. Ziegler K, Sanft C, Zimmer T, et al. Comparison of computed tomography, endosonography, and intraoperative assessment in TN staging of gastric carcinoma. Gut. 1993;34(5):604-610. doi:10.1136/ gut.34.5.604

36. Francois E, Peroux J, Mouroux J, et al. Preoperative endosonographic staging of cancer of the cardia. Abdom Imaging. 1996;21(6):483-487.

37. Massari M, Cioffi U, De Simone M, et al. Endoscopic ultrasonography for preoperative staging of gastric carcinoma. Hepato-gastroenterology. 1996;43(9):542-546.

38. Perng DS, Jan CM, Wang WM, et al. Computed tomography, endoscopic ultrasonography and intraoperative assessment in TN staging of gastric carcinoma. J Formos Med Assoc. 1996;95(5):378-385.

39. Hamada S, Akahoshi K, Chijiiwa Y, Nawata H, Sasaki I. Relationship between histological type and endosonographic detection of regional lymph node metastases in gastric cancer. Br J Radiol. 1997;70 (835):697-702. doi:10.1259/bjr.70.835.9245881

40. Akahoshi K, Chijiwa Y, Hamada S, et al. Pretreatment staging of endoscopically early gastric cancer with a $15 \mathrm{MHz}$ ultrasound catheter probe. Gastrointest Endosc. 1998;48(5):470-476. doi:10.1016/s00165107(98)70087-2

41. Hünerbein M, Ghadimi BM, Haensch W, Schlag PM. Transendoscopic ultrasound of esophageal and gastric cancer using miniaturized ultrasound catheter probes. Gastrointest Endosc. 1998;48(4):371-375. doi:10.1016/s0016-5107(98)70005-7
42. Wang JY, Hsieh JS, Huang YS, Huang CJ, Hou MF, Huang TJ. Endoscopic ultrasonography for preoperative locoregional staging and assessment of resectability in gastric cancer. Clin Imaging. 1998;22 (5):355-359.

43. de Manzoni G, Pedrazzani C, Di Leo A, et al. Experience of endoscopic ultrasound in staging adenocarcinoma of the cardia. Eur $J$ Surg Oncol. 1999;25(6):595-598. doi:10.1053/ejso.1999.0713

44. Nakamura K, Kamei T, Ohtomo N, Kinukawa N, Tanaka M. Gastric carcinoma confined to the Muscularis propria: how can we detect, evaluate, and cure intermediate-stage carcinoma of the stomach\&quest. Am J Gastroenterol. 1999;94(8):2251-2255. doi:10.1111/j.1572-0241.1999.01 301.x

45. Mancino G, Bozzetti F, Schicchi A, Schiavo M, Spinelli P, Andreola $\mathrm{S}$. Preoperative endoscopic ultrasonography in patients with gastric cancer. Tumori. 2000;86(2):139-141.

46. Tseng LJ, Mo LR, Tio TL, et al. Video-endoscopic ultrasonography in staging gastric carcinoma. Hepato-gastroenterology. 2000;47(33):897900.

47. Willis S, Truong S, Gribnitz S, Fass J, Schumpelick V. Endoscopic ultrasonography in the preoperative staging of gastric cancer: accuracy and impact on surgical therapy. Surg Endosc. 2000;14(10):951954. doi:10.1007/s004640010040

48. Chen $\mathrm{CH}$, Yang CC, Yeh YH. Preoperative staging of gastric cancer by endoscopic ultrasound: the prognostic usefulness of ascites detected by endoscopic ultrasound. J Clin Gastroenterol. 2002;35 (4):321-327. doi:10.1097/00004836-200210000-00008

49. Xi WD, Zhao C, Ren GS. Endoscopic ultrasonography in preoperative staging of gastric cancer: determination of tumor invasion depth, nodal involvement and surgical resectability. World $J$ Gastroenterol. 2003;9(2):254-257. doi:10.3748/wjg.v9.i2.254

50. Bhandari S, Shim CS, Kim JH, et al. Usefulness of three-dimensional, multidetector row CT (virtual gastroscopy and multiplanar reconstruction) in the evaluation of gastric cancer: a comparison with conventional endoscopy, EUS, and histopathology. Gastrointest Endosc. 2004;59 (6):619-626. doi:10.1016/s0016-5107(04)00169-5

51. Habermann CR, Weiss F, Riecken R, et al. Preoperative staging of gastric adenocarcinoma: comparison of helical CT and endoscopic US. Radiology. 2004;230(2):465-471. doi:10.1148/radiol.2302020828

52. Javaid G, Shah OJ, Dar MA, Shah P, Wani NA, Zargar SA. Role of endoscopic ultrasonography in preoperative staging of gastric carcinoma. ANZ J Surg. 2004;74(3):108-111.

53. Polkowski M, Palucki J, Wronska E, Szawlowski A, NasierowskaGuttmejer A, Butruk E. Endosonography versus helical computed tomography for locoregional staging of gastric cancer. Endoscopy. 2004;36(7):617-623. doi:10.1055/s-2004-814522

54. Shimoyama S, Yasuda H, Hashimoto M, et al. Accuracy of linear-array EUS for preoperative staging of gastric cardia cancer. Gastrointest Endosc. 2004;60(1):50-55. doi:10.1016/s0016-5107(04)01312-4

55. Lee YT, Ng EK, Hung LC, et al. Accuracy of endoscopic ultrasonography in diagnosing ascites and predicting peritoneal metastases in gastric cancer patients. Gut. 2005;54(11):1541-1545. doi:10.1136/ gut.2004.055772

56. Corrado Pedrazzani MD, Marco Bernini MD, Simone Giacopuzzi $\mathrm{MD}$, et al. Evaluation of Siewert classification in gastro-esophageal junction adenocarcinoma: what is the role of endoscopic ultrasonography? J Surg Oncol. 2005;91(4):226-231. doi:10.1002/jso.20302

57. Ang TL, Ng TM, Fock KM, Teo EK. Accuracy of endoscopic ultrasound staging of gastric cancer in routine clinical practice in Singapore. Chin J Dig Dis. 2006;7(4):191-196. doi:10.1111/j.14439573.2006.00270.x

58. Arocena MG, Barturen A, Bujanda L, et al. MRI and endoscopic ultrasonography in the staging of gastric cancer. Rev esp de enfermedades digestivas. 2006;98(8):582-590.

59. Iyer SG, Yan JSB, Yu LHK. Endoscopic ultrasonography for gastric cancer: does it influence treatment? Gastrointest Endosc. 2005;61(5): AB284. doi:10.1016/S0016-5107(05)01456-2 
60. Potrč S, Skalicky M, Ivanecz A. Does endoscopic ultrasound staging already allow individual treatment regimens in gastric cancer. Wien Klin Wochenschr. 2006;118(2):48-51. doi:10.1007/s00508-006-0552-y

61. Tsendsuren T, Jun SM, Mian XH. Usefulness of endoscopic ultrasonography in preoperative TNM staging of gastric cancer. World $J$ Gastroenterol. 2006;12(1):43-47. doi:10.3748/wjg.v12.i1.43

62. Barbour AP, Rizk NP, Gerdes H, et al. Endoscopic ultrasound predicts outcomes for patients with adenocarcinoma of the gastroesophageal junction. J Am Coll Surg. 2007;205(4):593-601. doi:10. 1016/j.jamcollsurg.2007.05.010

63. Bentrem D, Gerdes H, Tang L, Brennan M, Coit D. Clinical correlation of endoscopic ultrasonography with pathologic stage and outcome in patients undergoing curative resection for gastric cancer. Ann Surg Oncol. 2007;14(6):1853-1859. doi:10.1245/s10434-006-9037-5

64. Tan S-Y, Wang J-Y, Shen L, Luo H-S, Shen Z-X. Relationship between preoperative staging by endoscopic ultrasonography and MMP-9 expression in gastric carcinoma. World J Gastroenterol. 2007;13(14):2108-2112. doi:10.3748/wjg.v13.i14.2108

65. Blackshaw G, Lewis WG, Hopper AN, et al. Prospective comparison of endosonography, computed tomography, and histopathological stage of junctional oesophagogastric cancer. Clin Radiol. 2008;63 (10):1092-1098. doi:10.1016/j.crad.2008.04.006

66. Lok KH, Lee CK, Yiu HL, Lai L, Szeto ML, Leung SK. Current utilization and performance status of endoscopic ultrasound in a community hospital. J Dig Dis. 2008;9(1):41-47. doi:10.1111/j.14 43-9573.2007.00318.x

67. Park SR, Lee JS, Kim CG, et al. Endoscopic ultrasound and computed tomography in restaging and predicting prognosis after neoadjuvant chemotherapy in patients with locally advanced gastric cancer. Cancer. 2008;112(11):2368-2376. doi:10.1002/cncr.23483

68. Ahn HS, Lee HJ, Yoo MW, et al. Diagnostic accuracy of T and N stages with endoscopy, stomach protocol CT, and endoscopic ultrasonography in early gastric cancer. J Surg Oncol. 2009;99(1):20-27. doi:10.1002/jso. 21170

69. Repiso A, Gomez-Rodriguez R, Lopez-Pardo R, et al. Usefulness of endoscopic ultrasonography in preoperative gastric cancer staging: diagnostic yield and therapeutic impact. Rev esp de enfermedades digestivas. 2010;102(7):413-420.

70. Bohle W, Scheidig A, Zoller WG. Endosonographic tumor staging for treatment decision in resectable gastric cancer. $J$ Gastrointestinal Liver Dis. 2011;20(2):135-139.

71. Zheng Z, Yu Y, Lu M, et al. Double contrast-enhanced ultrasonography for the preoperative evaluation of gastric cancer: a comparison to endoscopic ultrasonography with respect to histopathology. $\mathrm{Am} \mathrm{J}$ Surg. 2011;202(5):605-611. doi:10.1016/j.amjsurg.2010.09.033
72. Kutup A, Vashist Y, Groth S, et al. Endoscopic ultrasound staging in gastric cancer: does it help management decisions in the era of neoadjuvant treatment? Endoscopy. 2012;44(06):572-576. doi:10. 1055/s-0032-1308950

73. Spolverato G, Ejaz A, Kim Y, et al. Use of endoscopic ultrasound in the preoperative staging of gastric cancer: a multi-institutional study of the US gastric cancer collaborative. J Am Coll Surg. 2015;220 (1):48-56. doi:10.1016/j.jamcollsurg.2014.06.023

74. Giganti F, Orsenigo E, Arcidiacono PG, et al. Preoperative locoregional staging of gastric cancer: is there a place for magnetic resonance imaging? Prospective comparison with EUS and multidetector computed tomography. Gastric Cancer. 2016;19(1):216-225. doi:10. 1007/s10120-015-0468-1

75. Serrano OK, Huang K, $\mathrm{Ng} \mathrm{N}$, et al. Correlation between preoperative endoscopic ultrasound and surgical pathology staging of gastric adenocarcinoma: a single institution retrospective review. J Surg Oncol. 2016;113(1):42-45. doi:10.1002/jso.24098

76. Kim GH, Park D, Kida M, et al. Accuracy of high-frequency catheter-based endoscopic ultrasonography according to the indications for endoscopic treatment of early gastric cancer. $J$ Gastroenterol Hepatol. 2010;25(3):506-511. doi:10.1111/j.1440-1746.2009.06111.x

77. Tsuzuki T, Okada H, Kawahara Y, et al. Usefulness and problems of endoscopic ultrasonography in prediction of the depth of tumor invasion in early gastric cancer. Acta Med Okayama. 2011;73(4):105-112.

78. Wiersema MJ, Vazquez-Sequeiros E, Wiersema LM. Evaluation of mediastinal lymphadenopathy with endoscopic US-guided fine-needle aspiration biopsy. Gastrointest Endosc. 2001;55(2):296-297.

79. Dumonceau JM, Polkowski M, Larghi A, et al. Indications, results, and clinical impact of endoscopic ultrasound (EUS)-guided sampling in gastroenterology: European Society of Gastrointestinal Endoscopy (ESGE) Clinical Guideline. Endoscopy. 2011;43(10):897-912. doi:10. 1055/s-0030-1256754

80. Yan C, Zhu ZG, Yan M, et al. Size of the largest lymph node visualized on multi-detector-row computed tomography (MDCT) is useful in predicting metastatic lymph node status of gastric cancer. $J$ Int Med Res. 2010;38(1):22. doi:10.1177/147323001003800103

81. Pei Q, Wang L, Pan J, Ling T, Lv Y, Zou X. Endoscopic ultrasonography for staging depth of invasion in early gastric cancer: a metaanalysis. J Gastroenterol Hepatol. 2015;30(11):1566-1573. doi:10.11 11/jgh.2015.30.issue-11

\section{Publish your work in this journal}

Cancer Management and Research is an international, peer-reviewed open access journal focusing on cancer research and the optimal use of preventative and integrated treatment interventions to achieve improved outcomes, enhanced survival and quality of life for the cancer patient.
The manuscript management system is completely online and includes a very quick and fair peer-review system, which is all easy to use. Visit http://www.dovepress.com/testimonials.php to read real quotes from published authors. 